\title{
Pulsed Electric Field Treatment of Saccharomyces cerevisiae Using Different Waveforms
}

\author{
S. Qin, I. V. Timoshkin, M. Maclean, M. P. Wilson, M. J. Given, T. Wang, J. G. Anderson \\ and S. J. MacGregor \\ Department of Electronic and Electrical Engineering, \\ University of Strathclyde, 204 George Street, \\ Glasgow, G1 1XW, United Kingdom
}

\begin{abstract}
Pulsed electric field (PEF) treatment can be used for non-thermal inactivation of microorganisms. The aim of this paper is to investigate PEF treatment of yeast, Saccharomyces cerevisiae, using three different field waveforms: square; non-oscillating exponential and oscillating exponential. The PEF system used in this paper consists of a pulsed power supply and a parallel-plane metallic electrodes treatment cell located in an air-pressurised chamber. PEF treatment of the yeast was conducted using electric field impulses with magnitudes of $67 \mathrm{kV} / \mathrm{cm}$ and $80 \mathrm{kV} / \mathrm{cm}$. The efficacy of the PEF treatment for inactivation of the yeast cells was assessed by comparison of the PEFtreated and untreated yeast populations. Results showed that $\sim 3-\log _{10}$ reduction in the yeast population can be achieved with 100 impulses using all tested waveforms. Amongst all three tested waveforms non-oscillating exponential impulses demonstrated improved PEF performance. The effect of duration of treatment and peak magnitude of the field on the PEF process is discussed.
\end{abstract}

Index Terms - Pulsed electric field, inactivation, yeast, Saccharomyces cerevisiae, field waveforms.

\section{INTRODUCTION}

HIGH voltage impulses can be used to generate electromechanical stresses in biological membranes allowing pores to be formed in the membrane [1]. The pores become irreversible if the transmembrane potential exceeds a critical value, and this irreversible electroporation results in the dysfunction of the biological membrane and the death of biological cell [2]. Therefore, pulsed electric field (PEF) treatment which results in irreversible electroporation can be used for inactivation of microorganisms. PEF induced microbiological effects have been intensively investigated in recent decades, and pulsed electric fields have been used for inactivation of yeast and bacteria [3-5], processing of liquid foodstuffs such as juice and milk $[6,7]$ and extraction of lipids from microalgae [8-10].

A key parameter of the PEF treatment is the critical field strength which triggers irreversible electroporation. It was found that irreversible processes of pore formation occur when the electrical potential across a membrane exceeds 0.9-1 V [2]. In several papers a relationship between the transmembrane potential and the external electric field strength has been investigated [11-13]. It was found that for a microbiological cell of $1 \mu \mathrm{m}$ in size, an external field of $10 \mathrm{kV} / \mathrm{cm}$ is required to trigger the electroporation effect [11]. However, experimental results

Manuscript received on 22 December 2014, in final form 28 February 2015, accepted 9 April 2015. presented in [12] showed that inactivation of yeast can be observed at a lower critical field value of $4.7 \mathrm{kV} / \mathrm{cm}$. In [3] a similar magnitude of the critical inactivation field was obtained: $4 \mathrm{kV} / \mathrm{cm}$ for Escherichia coli (bacteria), $6 \mathrm{kV} / \mathrm{cm}$ for Klebsiella pneumonia (bacteria) and $8 \mathrm{kV} / \mathrm{cm}$ for Candida albicans (yeast) and Pseudomonas aeruginosa (bacteria). However, in both [3] and [12], only $0.2-\log _{10}$ reduction of the microbial population was observed using the minimum (critical) field strength. When the field was increased to $7 \mathrm{kV} / \mathrm{cm}$, the population reduction of Saccharomyces cerevisiae increased to $5-\log _{10}$ [12]. It is also shown in [3], when the field was increased to $10 \mathrm{kV} / \mathrm{cm}$, the population reduction of E. coli increased to $3-\log _{10}$ and the population reduction of $C$. albicans increased to $2-\log _{10}$ when the field was increased to $12 \mathrm{kV} / \mathrm{cm}$. These results indicate that the field strength should exceed $10 \mathrm{kV} / \mathrm{cm}$ in order to achieve useful levels of inactivation. It has been shown that further increase in the field strength could result in a more prominent inactivation effect. For example, PEF impulses with magnitudes up to $110 \mathrm{kV} / \mathrm{cm}$ [14], and $200 \mathrm{kV} / \mathrm{cm}$ [15], were used to inactivate E. coli and Bacillus subtilis (bacteria). Such high field magnitudes require reasonably short (typically sub- $\mu \mathrm{s}$ ) duration of PEF impulses in order avoid formation of spark breakdown in the treatment cell. The results obtained in [14] demonstrate that for fields which exceed a value of $\sim 60 \mathrm{kV} / \mathrm{cm}$, the viability of $E$. coli decreases significantly as compared with lower field magnitudes. 
The effect of pulse duration on the PEF process has also been investigated $[5,16]$. It was shown that PEF impulses with a longer duration produce more efficient inactivation as compared with the same number of shorter impulses. Very few studies focused on the effect of pulse wave-shapes on the PEF process had been conducted [17, 18]. In [17] a comparison between square waveforms, exponential decaying waveforms and oscillatory decaying waveforms found the square waveforms resulted in the highest energy efficacy. The PEF impulses used in [17] had a peak field strength of $12 \mathrm{kV} / \mathrm{cm}$ and their duration was a few tens of $\mu \mathrm{s}$, depending on the wave-shape. In [18] mathematical analysis was conducted to find a correlation between the frequency components of the pulse waveform and the survival fraction of the microorganisms. These results are in good agreement with the experimental results reported in [17], which indicated that square waveforms with longest duration produce the strongest inactivation.

In the present study, PEF treatment of the yeast S. cerevisiae has been conducted using PEF impulses with magnitudes of $67 \mathrm{kV} / \mathrm{cm}$ and $80 \mathrm{kV} / \mathrm{cm}$ (which are above the threshold value of $60 \mathrm{kV} / \mathrm{cm}$ identified in [14]) and with three different wave-shapes: square, non-oscillating exponential and oscillating exponential wave-forms. The aim of this work is to provide a better understanding of the processes involved in the PEF inactivation of yeast at higher levels of electric field using mono-polar impulses with different wave-shapes, and with no reverse-polarity oscillations. This information can help in further optimisation of PEF wave-forms for practical applications. The yeast $S$. cerevisiae was selected for the present study as this type of yeast is commonly used in the food industry and in bio-medical applications. Also, the spherical shape of the S. cerevisiae cell is desirable for analytical modelling of the interaction of pulsed electric field with this microorganism which is planned in the future.

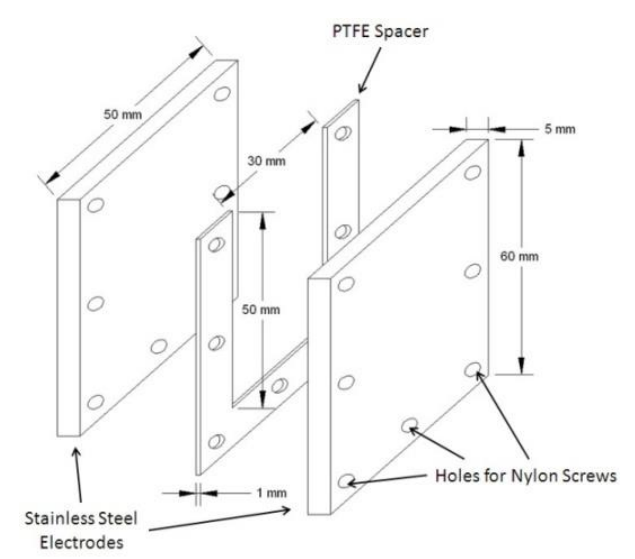

Figure 1. Schematic diagram of the PEF treatment cell.

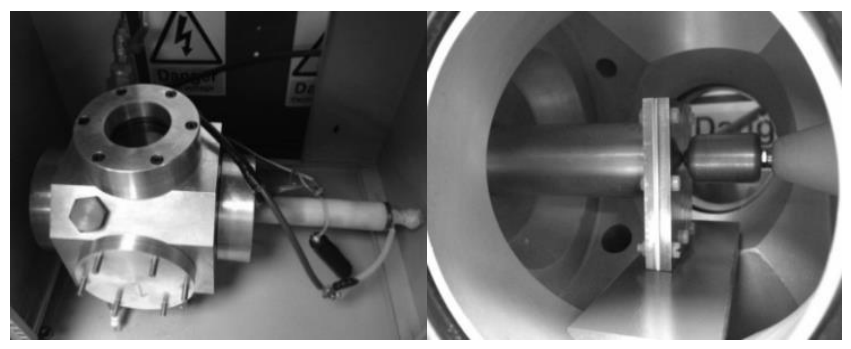

Figure 2. Pressurised chamber, (left), and the PEF treatment cell inside the chamber, (right).

\section{EXPERIMENTAL PROCEDURES}

\subsection{PEF SYSTEM AND WAVEFORM}

A schematic diagram of the PEF treatment cell is shown in Figure 1. The $50 \mathrm{~mm} \times 60 \mathrm{~mm}$ rectangular parallel-plane electrodes were made of stainless steel. The $1 \mathrm{~mm}$ interelectrode gap is maintained by a $1 \mathrm{~mm}$ PTFE spacer. The electrodes and the spacer are clamped tight by 7 sets of nylon screws. The yeast suspension is transferred into the cell through the open top of the treatment cell. Due to the small gap between the electrodes, an electric breakdown is likely to occur across the liquid-air interface under atmospheric pressure. In order to avoid this undesirable breakdown, the PEF treatment cell was placed inside a sealed metallic chamber as shown in Figure 2, which is pressurised to 7.5 bars using an air compressor. Thus, the PEF treatment takes place at elevated air pressure which suppresses development of interfacial spark breakdowns.

Three different voltage waveforms (square waveform, exponential waveform and oscillating exponential waveform), were used in this PEF study. Figure 3 shows the actual wave shapes across the PEF test cell. The square high voltage impulses were generated using a transmission line pulse generator (SAMTECH Ltd., UK) described elsewhere, [8]. This transmission line based system produces negative impulses of a magnitude up to $30 \mathrm{kV}$ with duration of $1 \mu \mathrm{s}$, and can operate with a pulse repetition rate from 0.1 to 10 pulses per second (pps). The exponential waveforms were generated by a $R C$ pulse discharge circuit which consists of a HVDC charging unit (Glassman, EH50P2), a HV capacitor with capacitance of $40 \mathrm{nF}$, a self-breakdown spark gap, and a high voltage cable which connects the output terminal of the capacitor with the PEF test cell. The magnitude of the voltage across the load is regulated by the inter-electrodes gap distance of the plasma closing switch and the pulse repetition rate is controlled by the current regulator of the $\mathrm{HV} \mathrm{DC}$ source. A $50 \Omega$ resistor was connected in parallel with the PEF treatment cell in order to achieve the non-oscillating exponential waveform. The oscillating exponential waveform was formed when the $50 \Omega$ resistor was removed. The voltage across the test cell was measured using a Tektronix HV probe with a bandwidth of $75 \mathrm{MHz}$, and the waveforms were recorded using a Tektronix TDS2024 oscilloscope with a bandwidth of $200 \mathrm{MHz}$ and a sampling rate of $2 \mathrm{GS} / \mathrm{s}$.

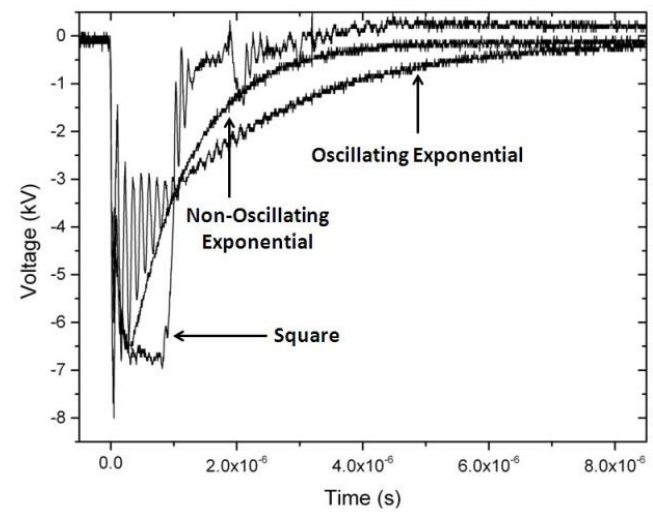

Figure 3. Actual waveforms obtained during the PEF treatment experiments. 


\subsection{PREPARATION OF THE YEAST SAMPLES}

The yeast used in this study was Saccharomyces cerevisiae MUCL 28749, obtained from The Belgian Co-ordinated Collections of Microorganisms. The yeast sample was cultured in $100 \mathrm{ml}$ Malt Extract Broth (Oxoid Ltd, UK) for 20 hours in a shaking incubator $(120 \mathrm{rpm})$ at $30^{\circ} \mathrm{C}$. Postincubation, the yeast suspension was centrifuged at $4300 \mathrm{rpm}$ for 10 minutes and re-suspended in $100 \mathrm{ml} 0.05 \%$ Mycological Peptone (Oxoid Ltd, UK) solution. The resulting yeast suspension had a population density of $\sim 10^{7}$ colonyforming units per millilitre (CFU/ml). To investigate the PEF inactivation of different concentrations of yeast, the yeast suspension was serially diluted to prepare populations from $10^{4}$ to $10^{7} \mathrm{CFU} / \mathrm{ml}$. $1.5 \mathrm{ml}$ yeast suspensions were then transferred into the test cell by sterile syringe. The conductivities of yeast suspensions measured at room temperature by a portable conductivity meter, Jenway 4150 , are given in Table 1. The resistance of the load (PEF test cell), $R$, and the peak conduction current through the cell during the PEF treatment, $I_{\text {peak }}$, were calculated using following equations:

$$
\begin{gathered}
R=d / \sigma A \\
I_{\text {peak }}=U_{\text {peak }} / R
\end{gathered}
$$

where $d$ is the distance between the electrodes, $\sigma$ is the conductivity of the yeast suspension, $A$ is the surface area of the electrode and $U_{\text {peak }}$ is the peak voltage during the PEF treatment. The results of this analysis for the peak field of 80 $\mathrm{kV} / \mathrm{cm}$ (which corresponds to the highest values of the conduction current during PEF tests) are shown in Table 1.

Table. 1 Conductivity of yeast suspension, resistance the PEF test cell and the peak conduction current.

\begin{tabular}{l|c|c|c|c}
\hline Population $(\mathrm{CFU} / \mathrm{ml})$ & $\sim 10^{7}$ & $\sim 10^{6}$ & $\sim 10^{5}$ & $\sim 10^{4}$ \\
\hline Conductivity $(\mu \mathrm{S} / \mathrm{cm})$ & 182 & 156 & 137 & 124 \\
\hline Test cell resistance $(\Omega)$ & 36.6 & 42.7 & 48.7 & 53.8 \\
\hline Peak current $(\mathrm{A})$ & 218 & 187 & 164 & 149 \\
\hline
\end{tabular}

\subsection{ASSESSMENT OF PEF PERFORMANCE}

Yeast samples with different initial populations were stressed with 25, 50 and $100 \mathrm{HV}$ impulses of different waveforms. Two voltage levels were used in the study, $6.7 \mathrm{kV}$ and $8 \mathrm{kV}$, with a pulse repetition rate of $1 \mathrm{pps}$. In the cases of the smooth and oscillating exponential waveforms, the peak voltages were set to the above values. The resulting peak electric field strength across the $1 \mathrm{~mm}$ inter-electrodes gap inside the PEF treatment cell was $67 \mathrm{kV} / \mathrm{cm}$ and $80 \mathrm{kV} / \mathrm{cm}$ respectively. In the case of the oscillating exponential waveform average peak fields were also calculated using an adjacent-averaging function in the Origin Pro 8 software package. These average field values for the two tested charging voltage peak levels are $47 \mathrm{kV} / \mathrm{cm}$ and $59 \mathrm{kV} / \mathrm{cm}$. PEF treated and untreated (control) yeast samples were plated onto Malt Extract Ager (Oxoid Ltd, UK) using spiral and spread plating methods. The populations of PEF treated and untreated yeast samples were enumerated and compared in order to assess the performance of the PEF impulses. The results are presented as the mean of surviving populations $\left(\log _{10} \mathrm{CFU} / \mathrm{ml}\right)$ and its standard deviation obtained from 3 independent PEF tests, in which fresh yeast samples were treated with pulsed electric field. Temperature of the yeast samples was measured before and after the treatment to identify any noticeable thermal effects.

\section{RESULTS AND DISCUSSIONS}

\subsection{TEMPERATURE EFFECTS}

Measurements of the temperature of yeast samples before and after the PEF treatment indicated that there was no significant temperature change during the PEF treatment. It was reported in [8] that low conductivity of liquid samples can reduce the heating effect. In the present study, in order to reduce thermal effects $0.05 \%$ Mycological Peptone was used as the suspending media, which provided a maximum conductivity of $182 \mu \mathrm{S} / \mathrm{cm}$ (in the case of $10^{7} \mathrm{CFU} / \mathrm{ml}$ yeast sample). This resulted in a minimal change in temperature of the treated sample of $1.5^{\circ} \mathrm{C}$. In contrast, the sample solutions with significantly higher conductivities in the range of a few tens of $\mathrm{mS} / \mathrm{cm}$ were used in [5] and [17] in PEF tests $(0.9 \%$ $\mathrm{NaCl}$ solution and apple juice, respectively). As a result, a significant heating effect of the PEF treatment was reported: temperature of the PEF treated samples increased by a few tens of ${ }^{\circ} \mathrm{C}$. Therefore, the insignificant temperature rise observed in the present paper is likely explained by the low conductivity of liquid solutions used in the tests.

\subsection{PEF INACTIVATION OF YEAST}

Figures 4-6 show the results of the PEF treatment using different field strengths and different waveforms: square, nonoscillating exponential and oscillating exponential wave shapes. Only two initial populations, the highest, $10^{7} \mathrm{CFU} / \mathrm{ml}$, and the lowest, $\sim 10^{4} \mathrm{CFU} / \mathrm{ml}$, are shown in these figures in order to provide clear viewing of the results. There were no significant differences in the behavior of the reaction kinetics for populations of $10^{6}$ and $10^{5} \mathrm{CFU} / \mathrm{ml}$ which are not shown in these Figures. In all cases, the PEF treatment with a higher field strength provided superior inactivation performance. As shown in Figures 4-6, the PEF treatment with $80 \mathrm{kV} / \mathrm{cm}$ provided $\sim 1-\log _{10}$ more efficient inactivation as compared with $67 \mathrm{kV} / \mathrm{cm}$ treatment by the same number of pulses.

The results of the PEF treatment shown in Figures 4-6 demonstrate that impulses with a higher field strength $(80 \mathrm{kV} / \mathrm{cm})$ provide on average $1-\log _{10}$ more efficient inactivation as compared with $67 \mathrm{kV} / \mathrm{cm}$ impulses for all initial populations. However, as the conductivity of the yeast solution depends on its initial yeast concentration, it is also interesting to evaluate the energy efficacy of the PEF process (population reduction as a function of specific energy, J/l) which is done in Section 3.4 of this paper. 


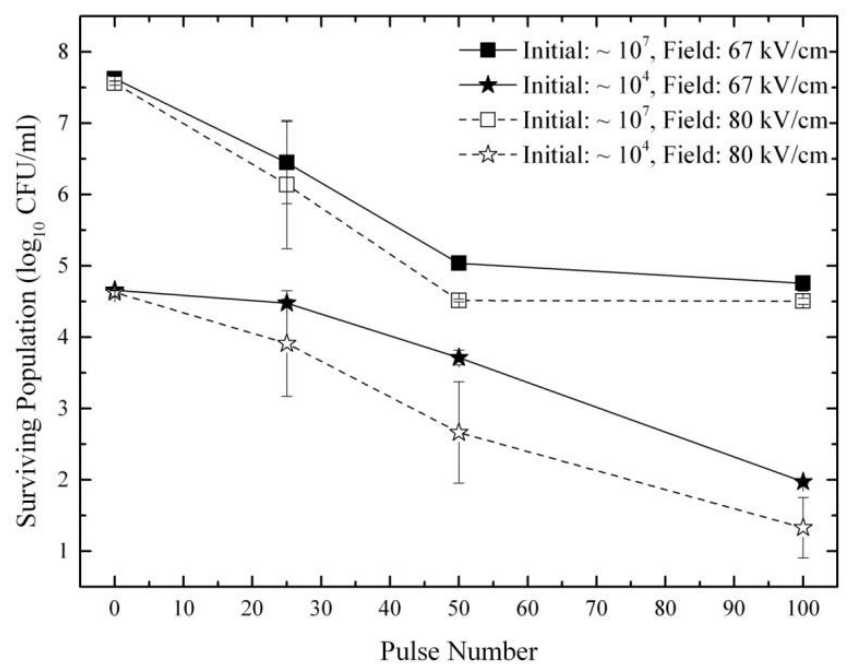

Figure 4. Surviving population of yeast $\left(\log _{10} \mathrm{CFU} / \mathrm{ml}\right)$ as a function of number of impulses. PEF treatment with square waveform of different initial populations. Solid line, $67 \mathrm{kV} / \mathrm{cm}$; Dash line, $80 \mathrm{kV} / \mathrm{cm}$. Error bars show standard deviation.

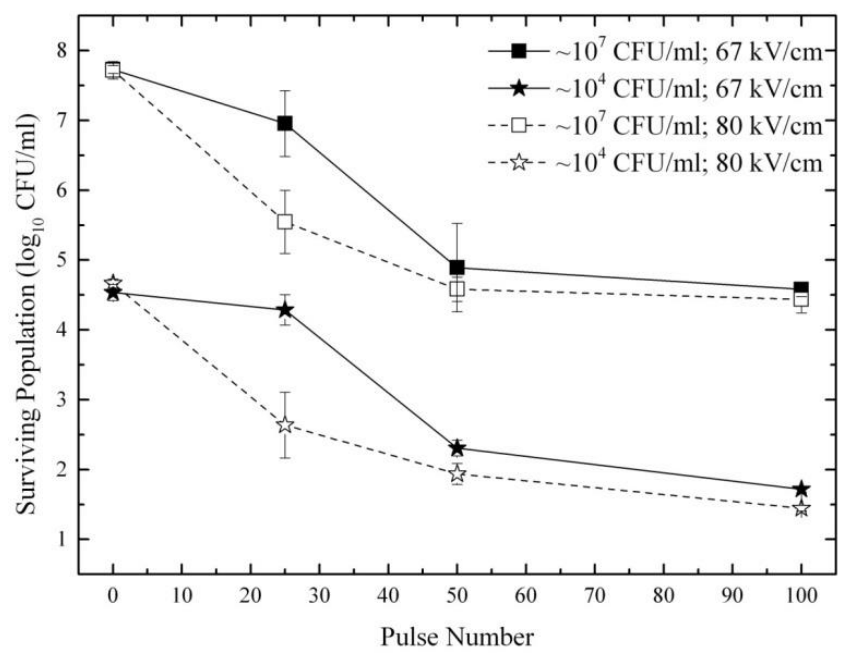

Figure 5. Surviving population of yeast $\left(\log _{10} \mathrm{CFU} / \mathrm{ml}\right)$ as a function of number of impulses. PEF treatment with non-oscillating exponential waveform of different initial populations. Solid line, $67 \mathrm{kV} / \mathrm{cm}$; Dash line, 80 $\mathrm{kV} / \mathrm{cm}$. Error bars show standard deviation.

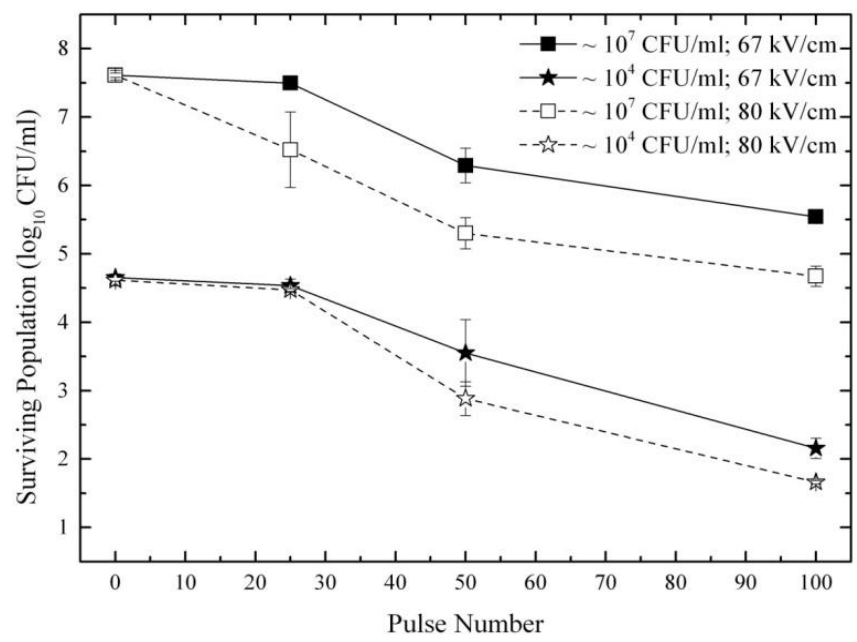

Figure 6. Surviving population of yeast $\left(\log _{10} \mathrm{CFU} / \mathrm{ml}\right)$ as a function of number of impulses. PEF treatment with oscillating exponential waveform of different initial populations. Solid line, $67 \mathrm{kV} / \mathrm{cm}$; dashed line, $80 \mathrm{kV} / \mathrm{cm}$. Error bars show standard deviation.

\subsection{COMPARISON BETWEEN DIFFERENT WAVEFORMS}

This section of the paper is focused on the analysis of the PEF process depending on the pulse waveform. The results of PEF inactivation using different field waveforms with the peak field of $67 \mathrm{kV} / \mathrm{cm}$ and $80 \mathrm{kV} / \mathrm{cm}$ are presented in Figure 7 and Figure 8 respectively. Again, only two initial populations, $\sim 10^{7} \mathrm{CFU} / \mathrm{ml}$ and $\sim 10^{4} \mathrm{CFU} / \mathrm{ml}$, are presented in these figures. As shown in Figures 7 and 8, the PEF treatment using the simple exponential waveform provided the best inactivation performance, while the PEF treatment using the oscillating exponential waveform had the lowest inactivation performance.

\subsection{TAILING EFFECT}

During the PEF trials, it was noticed that $3-\log _{10}$ reductions were achieved after 50 or 100 impulses regardless of the initial yeast population and the PEF waveform, resulting in a 'tailing' effect in the inactivation curves, as can be seen in Figures 7 and 8 . To investigate this effect, PEF treatment with an increased number of impulses (up to 250) was conducted and the results of these tests, shown in Figure 9, confirm the 'tailing' effect. This undesirable phenomenon was also observed in [17] and [19] but no explanation of the causes of this tailing effect has been reported in these papers.

In the present work, the tailing effect was examined using all waveforms and initial populations in order to identify the causes and to find possible solutions which would eliminate or reduce this undesirable effect. Figure 9 shows that an initial population of $\sim 10^{4} \mathrm{CFU} / \mathrm{ml}$ can be reduced to $\sim 10^{1} \mathrm{CFU} / \mathrm{ml}$ by $100 \mathrm{PEF}$ impulses. However the inactivation curves for the samples with an initial population of $10^{7} \mathrm{CFU} / \mathrm{ml}$ saturated at $10^{4} \mathrm{CFU} / \mathrm{ml}$ after 50 impulses. In this work it was observed that there was significant sedimentation of the yeast during the twenty minute period associated with pressurising the test chamber, applying the PEF treatment and depressurising the test chamber.

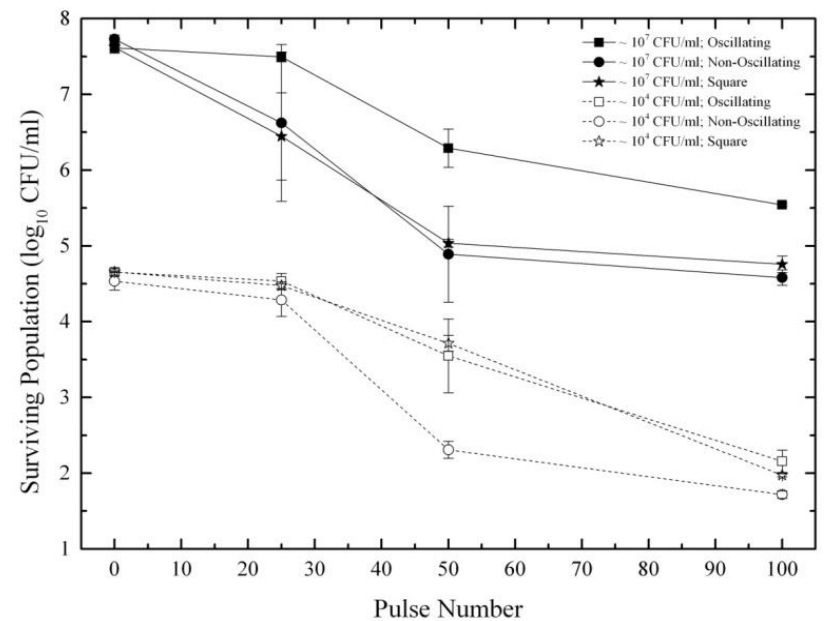

Figure 7. Surviving population of yeast $\left(\log _{10} \mathrm{CFU} / \mathrm{ml}\right)$ as a function of pulse number for $67 \mathrm{kV} / \mathrm{cm}$ waveforms: square waveform (star), non-oscillating exponential waveform (circle) and oscillating exponential waveform (square). Solid lines, $10^{7} \mathrm{CFU} / \mathrm{ml}$ initial population; dashed line, $10^{4} \mathrm{CFU} / \mathrm{ml}$ initial population. Error bars show standard deviation. 


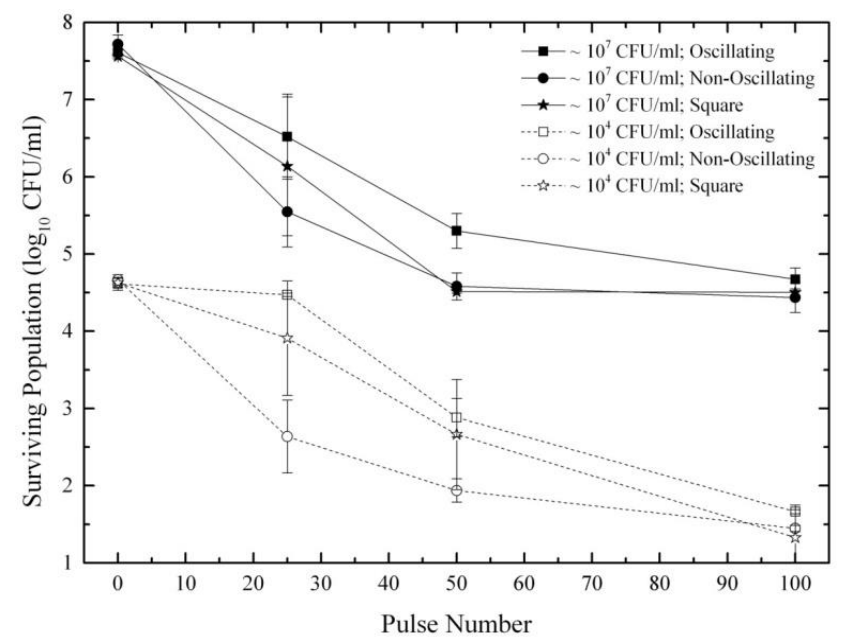

Figure 8. Surviving population of yeast $\left(\log _{10} \mathrm{CFU} / \mathrm{ml}\right)$ as a function of pulse number for $80 \mathrm{kV} / \mathrm{cm}$ waveforms: square waveform (star), non-oscillating exponential waveform (circle) and oscillating exponential waveform (square). Solid lines, $10^{7} \mathrm{CFU} / \mathrm{ml}$ initial population; dashed line, $10^{4} \mathrm{CFU} / \mathrm{ml}$ initial population. Error bars show standard deviation.

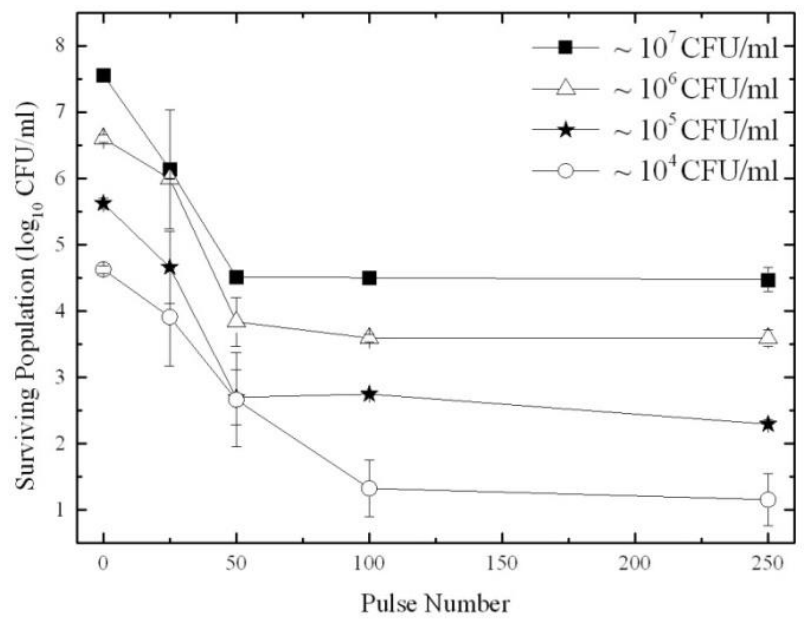

Figure 9. Surviving population of yeast $\left(\log _{10} \mathrm{CFU} / \mathrm{ml}\right)$ as a function of pulse number for larger numbers of impulses. $80 \mathrm{kV} / \mathrm{cm}$ square impulses. Error bars show standard deviation.

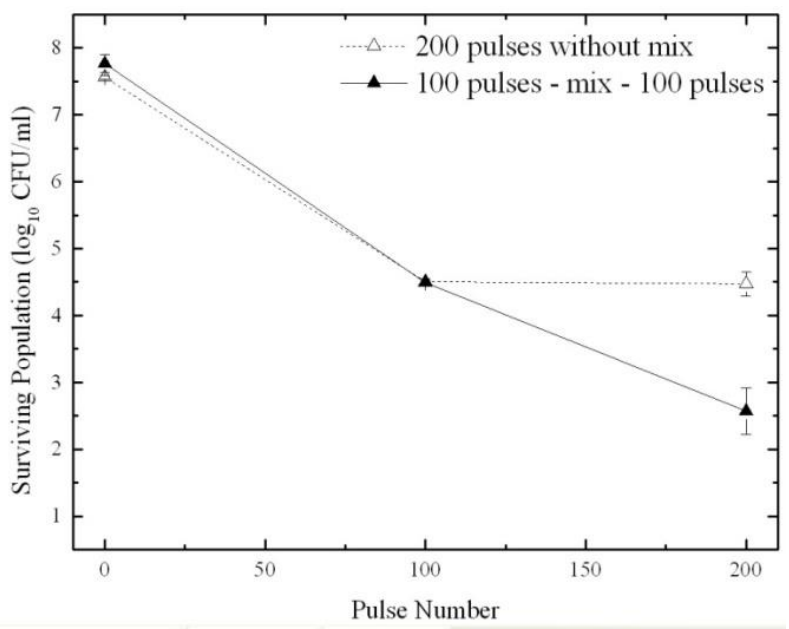

Figure 10. Comparison of the PEF performance between treatments with and without sample mixing after 100 pulses. Solid line and closed symbols represent the PEF treatment with mix process; Dash line and hollow spot represents PEF treatment without mix process. Error bars show standard deviation.
In [17] and [19], the batch PEF treatment process was used, which potentially may result in the tailing observed. In study [20] the tailing effect was reduced by using continuous PEF treatment (liquid flow through the PEF test cell), however no direct comparison between efficiencies of the batch and flow PEF processes of the same microorganisms was provided. Other factors, such as potential penetration of liquid with microorganisms in gaps between the electrodes and dielectric spacer (areas with reduced electric field) and clumping of microorganisms, might also contribute to the "tailing" effect in the inactivation process. More detailed analysis of actual causes of this "tailing" is required in future.

\subsection{SPECIFIC ENERGY CONSUMPTION}

Each impulse waveform delivers a different amount of energy to the liquid sample, and in order to determine the energy efficacy of the PEF process, specific energy has calculated using the following equation:

$$
E=V_{v o l} \cdot \sigma \cdot \int E^{2}(t) \cdot d t
$$

where $V_{v o l}$ is the volume of the PEF treatment cell, $\sigma$ is electrical conductivity of the yeast sample, and $E(t)$ is the time varying electric field strength across the PEF treatment cell.

Using equation (1), experimental impulsive waveforms obtained during the PEF treatment and conductivities of the yeast samples, the specific energies delivered by each impulse have been calculated. These energies are listed in Table 2.

Table 2. Specific energy delivered by the different PEF waveforms.

\begin{tabular}{c|c|c|c|c|c}
\hline \multirow{2}{*}{ Waveform } & \multirow{2}{*}{$\begin{array}{c}\text { Field } \\
\text { Strength }\end{array}$} & \multicolumn{4}{|c}{ Initial Population $(\mathrm{CFU} / \mathrm{ml})$} \\
\cline { 3 - 6 } & & $\sim 10^{7}$ & $\sim 10^{6}$ & $\sim 10^{5}$ & $\sim 10^{4}$ \\
\hline \multirow{2}{*}{ Square } & $67 \mathrm{kV} / \mathrm{cm}$ & $1.13 \mathrm{~J}$ & $0.97 \mathrm{~J}$ & $0.85 \mathrm{~J}$ & $0.77 \mathrm{~J}$ \\
\cline { 2 - 6 } & $80 \mathrm{kV} / \mathrm{cm}$ & $1.66 \mathrm{~J}$ & $1.41 \mathrm{~J}$ & $1.24 \mathrm{~J}$ & $1.12 \mathrm{~J}$ \\
\hline \multirow{2}{*}{$\begin{array}{c}\text { Non-Oscillating } \\
\text { exponential }\end{array}$} & $67 \mathrm{kV} / \mathrm{cm}$ & $0.90 \mathrm{~J}$ & $0.77 \mathrm{~J}$ & $0.64 \mathrm{~J}$ & $0.60 \mathrm{~J}$ \\
\cline { 2 - 6 } & $80 \mathrm{kV} / \mathrm{cm}$ & $1.13 \mathrm{~J}$ & $1.04 \mathrm{~J}$ & $0.96 \mathrm{~J}$ & $0.83 \mathrm{~J}$ \\
\hline $\begin{array}{c}\text { Oscillating } \\
\text { exponential }\end{array}$ & $67 \mathrm{kV} / \mathrm{cm}$ & $0.61 \mathrm{~J}$ & $0.69 \mathrm{~J}$ & $0.58 \mathrm{~J}$ & $0.55 \mathrm{~J}$ \\
\cline { 2 - 6 } & $80 \mathrm{kV} / \mathrm{cm}$ & $0.96 \mathrm{~J}$ & $0.96 \mathrm{~J}$ & $0.83 \mathrm{~J}$ & $0.80 \mathrm{~J}$ \\
\hline
\end{tabular}

From here it can be seen that the largest amount of specific energy was delivered by a single square impulse, while the minimum amount of specific energy was delivered by a single oscillating exponential impulse. Figure 11 shows surviving population of yeast as a function of specific energy delivered to the test cell during the PEF treatment for three tested waveforms: non-oscillating exponential, oscillating exponential and square with peak field of $67 \mathrm{kV} / \mathrm{cm}$ and $80 \mathrm{kV} / \mathrm{cm}$. All three waveforms provided similar PEF inactivation tendencies: the surviving population of yeast reduces gradually as the specific energy increases. Nonoscillatory wave form shows larger reduction in surviving population for the same specific energy as compared with two other wave-forms. However, it was reported in [17] and [18] that the square voltage waveform was more energy efficient than exponentially decaying waveforms in the PEF process. In [17], both waveforms produced the same peak field strength and delivered the same amount of energy per impulse. It was found that the PEF treatment using a square-wave required a lower number of impulses to achieve the same inactivation 
result. However, the peak field used in [17] was $12 \mathrm{kV} / \mathrm{cm}$, which only slightly exceeded the critical value assumed to be $10 \mathrm{kV} / \mathrm{cm}$. For the waveforms reported, the field strength was above $10 \mathrm{kV} / \mathrm{cm}$ for only $20 \mu \mathrm{s}$ in the case of a single exponential impulse, while in the case of a single square impulse the field strength was above $10 \mathrm{kV} / \mathrm{cm}$ for $\sim 50 \mu \mathrm{s}$.

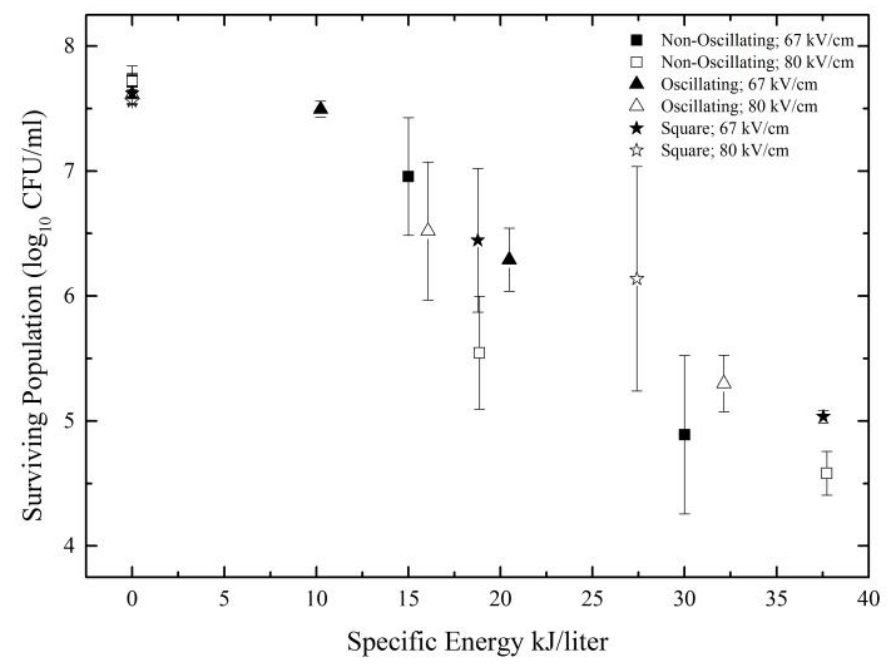

Figure 11. Energy efficacy of PEF treatment using non-oscillating exponential (square), Square (triangle) and Oscillating (star) waveforms with $67 \mathrm{kV} / \mathrm{cm}$ (solid) and $80 \mathrm{kV} / \mathrm{cm}$ (empty). Initial population of yeast was $10^{7} \mathrm{CFU} / \mathrm{ml}$. Error bars show standard deviation.

In the present study, the duration of the non-oscillating exponential and square parts of impulses which exceeded $10 \mathrm{kV} / \mathrm{cm}$ were $2.5 \mu \mathrm{s}$ and $1 \mu \mathrm{s}$ respectively. Therefore, a correlation between the effective impulse duration (period where the field strength is above $10 \mathrm{kV} / \mathrm{cm}$ ) and the PEF performance exists in the results reported in [17] and the present study. Thus, the difference in time during which the field exceeded the critical value may explain the advantage of the square impulses over the exponential waveform used in [17]. The waveform with the longer effective duration results in a better PEF performance.

In the present study, in spite of a longer effective duration, the oscillating exponential impulses demonstrated lower PEF performances compared with the non-oscillating exponential impulses. This can be explained by lower average peak fields and deep field oscillations at the peak of the former waveform.

As is indicated in Section 2.3 the average peak fields in the case of the oscillating exponential wave form are $47 \mathrm{kV} / \mathrm{cm}$ and $59 \mathrm{kV} / \mathrm{cm}$ for the two levels of charging voltage. These values are lower than the peak field magnitudes of the exponential and square waveforms, $67 \mathrm{kV} / \mathrm{cm}$ and $80 \mathrm{kV} / \mathrm{cm}$ correspondingly. This may help to explain inferior PEF inactivation results achieved with the oscillating exponential impulses as the average peak fields of $47 \mathrm{kV} / \mathrm{cm}$ and 59 $\mathrm{kV} / \mathrm{cm}$ are close or below the $60 \mathrm{kV} / \mathrm{cm}$ threshold which was identified in [14] as being the magnitude below which electric fields demonstrate noticeably lower PEF performance.

Also, the oscillating exponential wave-forms have deep field oscillations at their peaks, duration of the $1 / 4$ period of these oscillations is $\sim 30 \mathrm{~ns}$. However, according to the model of transient membrane charging developed in [13], time required to achieve the maximum field across yeast membrane is $\sim 1 \mu \mathrm{s}$ and during $\sim 30 \mathrm{~ns}$ the field across the membrane can reach only $\sim 10 \%$ of its potential maximum value.

Therefore, in order to achieve high efficacy in the PEF inactivation process it is desirable to increase duration of exposure to the maximum field and to the critical field. However, it is not clear which of these two factors play a dominant role and further investigation is required to clarify their contribution to pulsed electric field inactivation.

\section{CONCLUSION}

The present study is focused on investigation of the PEF inactivation process of the yeast Saccharomyces cerevisiae using three types of field impulses (square, non-oscillating exponential and oscillating exponential impulses) with pulse duration of a few $\mu \mathrm{s}$ and two levels of field strength of $67 \mathrm{kV} / \mathrm{cm}$ and $80 \mathrm{kV} / \mathrm{cm}$. The results of this study show that PEF performance depends on multiple factors.

It was established that measures which minimise the sedimentation of the yeast during the batch PEF treatment, (either by using continuous flow PEF system, [20], or by applying a mixing procedure), improves PEF performance.

It was shown that surviving population of yeast depends on the magnitude of the PEF pulses: pulses with a higher peak field magnitude produce a greater inactivation effect as compared with the same number of pulses with a lower field peak magnitude. However, the specific energy delivered by the same number of pulses with different field magnitudes is different. Therefore, further analysis of the obtained PEF inactivation curves has been conducted in order to establish the dependency of PEF performance on the specific energy delivered to the test cell. It was demonstrated that surviving population of yeast reduces with an increase in the specific energy delivered to the cell and the rate of this decrease does not depend on the peak field magnitude (for pulses with magnitudes of $67 \mathrm{kV} / \mathrm{cm}$ or $80 \mathrm{kV} / \mathrm{cm}$ ).

Three types of waveforms were used in the PEF tests and it was shown that non-oscillating exponential impulses provided better PEF performance: higher decrease in surviving yeast population for the same number of impulses and the same specific energy as compared with two other waveforms. It was also shown that lower effective duration of the waveform may result in lower PEF performance. Therefore, in order to optimise PEF inactivation of yeast all these factors (the maximum field strength, the critical pulse duration and the specific energy) should be taken into account. However, further investigations are required in order to establish individual role of each of these factors in the PEF treatment.

\section{REFERENCES}

[1] S. Toepfl, V. Heinz, and D. Knorr, Pulsed Electric Fields Technology for the Food Industry: Fundamentals and Applications, Springer-Verlag, 2006.

[2] U. Zimmermann, "Electrical Breakdown, Electropermeabilization and Electrofusion", Rev. Physiol. Biochem. Pharmacol., Vol. 105, No. 6, pp. 175-256, 1986.

[3] H. Hulsheger, J. Potel, and E.G. Niemann, "Electric Field Effects on Bacteria and Yeast Cells", Radiation and Enironmental Biophysics, Vol. 22, pp. 149-162, 1983. 
[4] B. L. Qin, G. V. Barbosa-Canovas, B. G. Swanson, P. D. Pedrow, and R.G. Olsen, "Inactivating Microorganisms Using a Pulsed Electric FieldContinuous Treatment System," IEEE Trans. Industry Applications, Vol. 34, No. 1, pp. 43-50, 1998.

[5] K. Aronssona, M. Lindgrena, B. R. Johanssonb, and U. Ronner, "Inactivation of Microorganisms Using Pulsed Electric Fields:the Influence of Process Parameters on Escherichia Coli, Listeria Innocua, Leuconostoc Mesenteroides andSaccharomyces Cereisiae", Innovative Food Sci. Emerging Technologies, Vol. 2, No. 1, pp. 41-54, 2001.

[6] P. S. Brito, H. Canacsinh, J. P. Mendes, L. M. Redondo, and M. T. Pereira, "Comparison between Monopolar and Bipolar Microsecond Range Pulsed Electric Fields in Enhancement of Apple Juice Extraction," IEEE Trans. Plasma Sci., Vol. 40, No. 10, pp. 2348-2354, 2012.

[7] H. Jaeger, N. Meneses, and D. Knorr, "Impact of PEF Treatment Inhomogeneity such as Electric Field Distribution, Flow Characteristics and Temperature Effects on the Inactivation of E. Coli and Milk Alkaline Phosphatase", Innovative Food Sci. Emerging Technologies, Vol. 10, No. 4, pp. 470-480, 2009.

[8] S. Qin, I. Timoshkin, M. Wilson, M. Maclean, S. MacGregor, M. Given, J. Anderson, and T. Wang, "Pulsed Electric Field Treatment of Microalgae: Inactivation Tendencies and Energy Consumption", IEEE Trans. Plasma Sci., Vol. 42, No. 10, pp. 3191-3196, 2014.

[9] M. D. A. Zbinden, B. S. M. Sturm, R. D. Nord, W. J. Carey, D. Moore, H. Shinogle, and S. M. Stagg-Williams, "Pulsed Electric Field (PEF) as an Intensification Pretreatment for Greener Solvent Lipid Extraction from Microalgae," Biotechnol. Bioeng., Vol. 110, No. 6, pp. 1605-1615, 2013.

[10] C. Eing, M. Goettel, R. Straessner, C. Gusbeth, and W. Frey, "Pulsed Electric Field Treatment of Microalgae-Benefits for Microalgae Biomass Processing," IEEE Trans. Plasma Sci., Vol. 41, No. 10, pp. 2901-2907, 2013.

[11] K. H. Schoenbach, F. E. Peterkin, R. W. Alden, III, and S. J. Beebe, "The Effect of Pulsed Electric Fields on Biological Cells: Experiments and Applications", IEEE Trans. Plasma Sci., Vol. 25, No. 2, pp. 284 $292,1997$.

[12] T. Grahl, and H. Markl, "Killing of Microorganisms by Pulsed Electric Fields", Appl. Microbiology Biotechnology, Vol. 45, No. 1-2, pp. 148157, 1996.

[13] I. Timoshkin, S. MacGregor, R. Fouracre, B. Crichton, and J. Anderson, "Transient Electrical Field across Cellular Membranes: Pulsed Electric Field Treatment of Microbial Cells", J. Phys. D: Appl. Phys., Vol. 39, pp. 569-603, 2006.

[14] R. Narsetti, R. D. Curry, K. F. McDonald, T. E. Clevenger, and L. M. Nichols, "Microbial Inactivation in Water Using Pulsed Electric Fields and Magnetic Pulse Compressor Technology", IEEE Trans. Plasma Sci., Vol. 34, No.4, pp. 1386-1393, 2006.

[15] B. M. Novac, F. Babakhr, I. R. Smith, L. Pecastaing, R. Ruscassic, A. D. Ferron, and P. Pignolet, "Demonstration of a Novel Pulsed Electric Field Technique Generating Neither Conduction Currents Nor Joule Effects", IEEE Trans. Plasma Sci., Vol. 42, No. 1, pp. 216-228, 2014.

[16] J. Beveridge, S. MacGregor, J. Anderson, and R. Fouracre, "The Influence of Pulse Duration on the Inactivation of Bacteria using Monopolar and Bipolar Profile Pulsed Electric Fields," IEEE Trans. Plasma Sci., Vol. 33, No. 4, pp. 1287-1293, 2005.

[17] B. L. Qin, Q. Zhang, G. V. Barbosa-Canovas, B. G. Swanson, and P. D. Pedrow, "Inactivation of Microorganisms by Pulsed Electric Fields of Different Voltage Waveforms," IEEE Trans. Dielectr. Electr. Insul., Vol. 1, No. 6, pp. 1047-1057, 1994.

[18] P. Love, "Correlation of Fourier Transforms of Pulsed Electric Field Waveform and Microorganism Inactivation", IEEE Trans. Dielectr. Electr. Insul., Vol. 5, No. 1, pp. 142-147, 1998.

[19] J. R. Beveridge, S. J. MacGregor, L. Marsili, J. G. Anderson, N. J. Rowan, and O. Farish, "Comparison of the Effectiveness of Biphase and Monophase Rectangular Pulses for the Inactivation of Microorganisms using Pulsed Electric Fields," IEEE Trans. Plasma Sci., Vol. 30, No. 4, pp. 1525-1531, 2002.

[20] J. R. Beveridge, K. Wall, S. J. MacGregor, J. G. Anderson, and N. J. Rowan, "Pulsed Electric Field Inactivation of Spoilage Microorganisms in Alcoholic Beverages", Proc. IEEE, Vol. 92, No. 7, pp. 1138-1147, 2004.

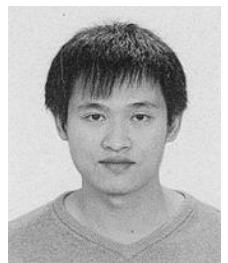

Si Qin was born in Guangxi, China, in 1988. He received the B.Eng. (with honours) degree in electronic and electrical engineering in 2011, and the M.Sc. degree in electrical power engineering with business in 2012, both from the University of Strathclyde, Glasgow, U.K. $\mathrm{He}$ is currently pursuing the Ph.D. degree in electronic and electrical engineering at the University of Strathclyde.

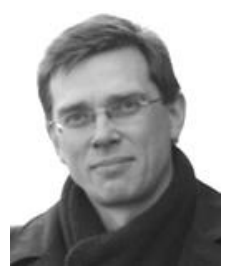

Igor V. Timoshkin (M'07-SM'14) received a degree in physics from the Moscow State University (Russia) in 1992, and the Diploma and the Ph.D. degree from the Imperial College of Science, Technology and Medicine, (London, UK) in 2001. After graduation from MSU he worked as a Researcher at Moscow State AgroEngineering University, and then at the Institute for High Temperatures of Russian Academy of Sciences before moving to ICSTM in 1997. He joined the Department of Electronic and Electrical Engineering of the University of Strathclyde (Glasgow, UK) in 2001 where he became a Senior Lecturer in 2011. His research interests include properties of solid and liquid dielectric materials, electronics of plasma discharges in condensed media, practical applications of electro-hydraulic and high-power ultrasound pulses, biodielectrics and effects of electromagnetic fields on biological objects.

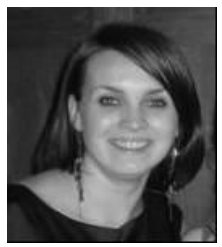

Michelle Maclean was born on the Isle of Lewis, Scotland, in 1980. She received the B.Sc. $\left(1^{\text {st }}\right.$ class honors) degree in Microbiology and Immunology in 2002, and the Ph.D. degree in electronic and electrical engineering in 2006, both from the University of Strathclyde, Glasgow, U.K. She is presently working as a Lecturer at the University of Strathclyde, and her interdisciplinary research work involves the development and application of novel electro-technologies for biological decontamination and sterilization applications in clinical and public health environments. She is a member of The Society for General Microbiology and The American Society of Microbiology.

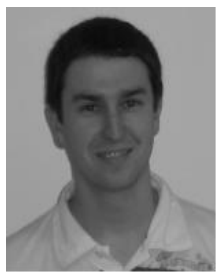

Mark P. Wilson (M'10) was born in Stranraer, Scotland, in 1982. He received the B.Eng. (with honours), M.Phil., and Ph.D. degrees in electronic and electrical engineering from the University of Strathclyde, Glasgow, U.K., in 2004, 2007, and 2011, respectively. He is presently working as a Teaching Associate at the University of Strathclyde, where he continues to investigate surface flashover of solids immersed in insulating oil. Mark is a member of the IEEE Nuclear and Plasma Sciences Society, from whom he received a Graduate Scholarship Award in 2011, the IEEE Dielectrics and Electrical Insulation Society, and the IET.

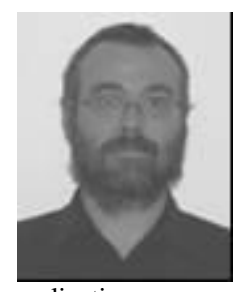

Martin J. Given (M'99-SM'11) is currently a Senior Lecturer in the Department of Electronic and Electrical Engineering at the University of Strathclyde. He received a degree in physics from the University of Sussex in 1981 and a PhD in electronic and electrical engineering from the University of Strathclyde in 1996. His research interests include, ageing processes and condition monitoring in solid and liquid insulation systems, high speed switching and pulse power applications.

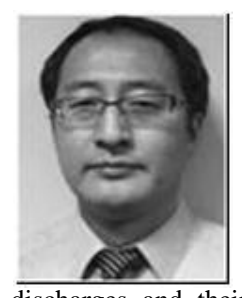

Tao Wang received the B.Eng and M.Sc degrees from Northeast China Dianli University (China) in 1993 and 1996 respectively, and the Ph.D. degree from the University of Strathclyde (Glasgow, UK) in 2005. He then joined the Newland Entech as a research fellow developing high efficiency industrial ozone generator. He joined the department of Electronic and Electrical Engineering of University of Strathclyde as a lecturer in 2010. His research interests include non-thermal gas discharges and their applications in gas synthesis, water disinfection and advanced oxidation process in water. 


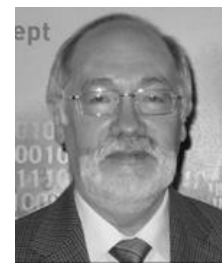

John Anderson was born in Glasgow, U.K., on September 2, 1942. He received the B.Sc. degree in applied microbiology in 1968, and the Ph.D. degree in fungal physiology in 1971, both from the University of Strathclyde, Glasgow. Since 1971, he has been with the

Department of Bioscience and Biotechnology, University of Strathclyde, where he became a Professor of Microbiology and Head of Department. $\mathrm{He}$ is currently an Emeritus Professor at the University of Strathclyde. His research interests include various aspects of food, biomedical and environmental microbiology with interdisciplinary collaboration on the application of electro-technologies for electronic pasteurization and sterilization.

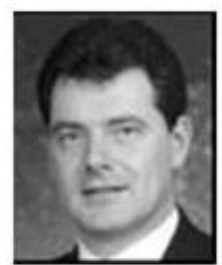

Scott J. MacGregor (M'95-SM'14) received the B.Sc. and $\mathrm{Ph} . \mathrm{D}$. degrees from the University of Strathclyde, Glasgow, U.K., in 1982 and 1986, respectively. He became a Pulsed Power Research Fellow in 1986 and a Lecturer in pulsed-power technology in 1989. In 1994, he became a Senior Lecturer, with a promotion to Reader and Professor of High Voltage Engineering, in 1999 and 2001, respectively. From 2010 he became a Dean of the Engineering Faculty of the University of Strathclyde. His research interests include high-voltage pulse generation, high-frequency diagnostics, high-power repetitive switching, high-speed switching, electronic methods for food pasteurization and sterilization, generation of high-power ultrasound (HPU), plasma channel drilling, pulsedplasma cleaning of pipes, and stimulation of oil wells with HPU. 